\title{
ERRATUM
}

\section{Further evidence for association between ErbB4 and schizophrenia and influence on cognitive intermediate phenotypes in healthy controls}

KK Nicodemus, A Luna, R Vakkalanka, T Goldberg, M Egan, RE Straub and DR Weinberger

Molecular Psychiatry (2007) 12, 883; doi:10.1038/sj.mp.4001963

Correction to: Molecular Psychiatry (2006) 11, 10621065; doi:10.1038/sj.mp.4001878

Following publication of the above article, the authors noted that two copies of Table 1 (an incomplete version on page 1063 and a complete version on page 1064) were incorrectly printed. The full table appears on page 1064. 